Ennis, C.D. (1991). Discrete thinking skills in two teachers' physical education classes. Elementary School Journal, 91(5), 473-487.

Made available courtesy of the University of Chicago Press: http://www.press.uchicago.edu/

***Reprinted with permission. No further reproduction is authorized without written permission from the University of Chicago Press. This version of the document is not the version of record. Figures and/or pictures may be missing from this format of the document. ${ }^{* * *}$

\section{Discrete Thinking Skills in Two Teachers' Physical Education Classes}

\author{
Catherine D. Ennis
}

University of Maryland

The Elementary School Journal

Volume 91, Number 5

(C) 1991 by The University of Chicago. All rights reserved.

0013-5984/91/9105-0009\$01.00

\begin{abstract}
Integrating thinking skills such as focusing, information gathering, and organization into all subjects is becoming increasingly important in elementary schools. The nonacademic subjects of physical education, art, and music can provide opportunities for teaching thinking skills. In this study, 2 physical education programs (8 classes) were examined for the presence of opportunities to use thinking skills. The programs were taught by 2 expert physical education teachers at different schools using the Logsdon physical eduction curriculum. Data were analyzed using constant comparison. Results indicated that teachers used deductive and inductive strategies associated with teacher- and student-structured experiences to encourage student metacognition. Properties of the data categories represented discrete thinking skills, such as attention focusing, comparing, and analyzing, typically associated with thinking-readiness experiences.
\end{abstract}

Assisting students to improve their thinking skills is increasingly recognized as a primary goal of education (Costa, 1985). Researchers have defined a range of skills associated with thinking. Skills can be conceptualized on a continuum based on the level of complexity required or the difficulty of the problem to be addressed. The broad term "cognitive processes" refers to complex operations that usually require substantial time and effort and the integration of general and specific knowledge (Marzano et al., 1988). "Critical thinking" is the term most frequently used in the literature to encompass a variety of thoughtful actions from highly specific mathematical problems to more general reasoning abilities. Sternberg (1985, p. 46), for example, defined critical thinking as "the mental processes, strategies and representations peo- 
ple use to solve problems, make decisions, and learn new concepts." Ennis (1985, p. 54) presented a much broader interpretation of critical thinking, defining it "as reasonable, reflective thinking that is focused on deciding what to believe or do." Elementary thinking consists of basic skills that are essential to cognitive functioning in a variety of dimensions (Marzano et al., 1988). Basic thinking skills are useful within a particular context and facilitate learning of content knowledge. They may involve such skills as focusing, information gathering, remembering, and organizing.

A variety of methods have been proposed to teach thinking skills. These are typically organized within the two major categories of content-specific and contentgeneral methods. Advocates of content-specific methods argue that each discipline embraces a set of unique thinking strategies or heuristics that can be best learned within its related knowledge base (Schoenfeld \& Herrmann, 1982). Research within this perspective is seeking to isolate problem-solving heuristics that experts use within particular disciplines (Perkins \& Solomon, 1989). Teaching strategies developed from this position assist students in utilizing context- and content-specific heuristics that facilitate problem solution (Pitt, 1983; Polya, 1957). Conversely, proponents of the teaching of general thinking strategies identify components of reasoning or matrices of thinking skills (e.g., Safrit, Ennis, \& Nagle, 1988; Sternberg, 1985) that are believed to be effective in examining and solving a wide range of problems. Because these skills are useful within a variety of disciplines, they can be integrated and reinforced across the curriculum.

The integrated approach to the teaching of thinking involves a cross-disciplinary effort to introduce, support, and maintain key thinking skills by using examples of content or problems from many disciplines. Recent articles supporting the integrated approach offer suggestions for incorporating thinking skills in social studies (e.g., Beyer, 1985;
Solomon, 1987), mathematics (e.g., Wirtz, 1985), reading (e.g., Jones, 1985), and writing (e.g., Glatthorn, 1985). Although Presseisen (1985) suggested that creative thinking might be appropriate in nonacademic areas such as art and music, there have been few efforts to examine the potential for teaching thinking skills as part of physical education.

The study reported here was conducted to examine thinking skills included as part of two elementary physical education programs taught by expert physical education specialists. The significance of this research lies in the examination of basic thinking skills in a subject that has been overlooked as a potential resource for enhancing and reinforcing cognitive skills. Most students participate in physical education classes at some point during the first 6 years of formal schooling. The intensity of the experience may range from daily classes taught by a specialist to a weekly session taught by the classroom teacher. Physical education provides an excellent opportunity to increase the academic learning time designated for cognitive skills and the positive attitudes of young students toward thinking. More specifically, reinforcing cognitive skills in physical education may contribute as much as 3 hours each week to the cognitive learning time available to students. By emphasizing the characteristics of basic thinking skills in experientially different environments, teachers build relevant associations that contribute to cognitive transfer (Perkins \& Salomon, 1989). Second, integrating thinking skills into a subject that most students enjoy can contribute to positive attitudes. Traditionally, physical education has proven interesting and enjoyable to some students who have limited success in other subjects. As these students begin to associate thinking skills with activities in which they are successful, they are more likely to perceive the skills' relevance to academic and other experiences. Most elementary students eagerly anticipate physical education class. Integrating thinking skills into 
physical education can increases students' exposure to these skills and foster the development of positive attitudes toward thinking.

\section{Method}

This study was conducted within the symbolic interactionist paradigm (Jacob, 1987) and was designed to include the teachers' interpretations of the educational settings. The symbolic interactionist tradition within qualitative research is responsive to both the conscious perceptions of the participants and the unconscious meanings that participants assign to events. The rationale for the use of the methodology was based on the premise that teachers are active participants in the instructional setting and thus both influence and respond to the learning environment. The teachers were not informed of the exact purpose of the research prior to the study because such knowledge might have affected their planning and changed their normal behavior. They were told that the purpose of the study was to examine physical education classes taught with the Logsdon et al. (1984) curriculum approach and that they would receive a report of the findings at the completion of the study. Teachers were formally interviewed at the conclusion of the study and asked to respond to questions regarding both their perceptions of the use of thinking skills in their classes and the investigator's interpretation of events.

\section{Selection of Physical Education Programs}

Although it can be argued that many physical education programs have the potential to encourage thinking skills, one approach appears to have the conceptual and theoretical sophistication to substantiate these claims at the elementary level. Logsdon et al.'s (1984) program combines Laban's (1971) fundamental movement principles with the mechanical principles of force similar to those taught in an elementary science class. The curriculum is struc- tured based on a modification of Laban's four movement aspects of body, space, effort, and relationships. In other words, students in these physical education classes were primarily interested in answering four basic questions about movement: What can my body do? Where is my body moving? How is my body performing the movement? What relationships to other people, equipment, or boundaries are occurring as I move? This approach provides a carefully articulated body of knowledge as the focus of student thinking. The cognitive component is emphasized within the Logsdon philosophy in the following statement: "Students are capable of making decisions, and education is responsible for helping students develop the ability to make reasoned choices so that they can adjust their role appropriately as their social and physical surroundings change. Physical education, to share meaningfully in education, must provide experiences that improve the ability to move, that engage thought processes, and that contribute positively to the development of a value system and the esteem in which students regard themselves and others" (Logsdon et al., 1984, p. 13). It seems logical to assume that the Logsdon approach would be conducive to integrating the development of thinking skills with the study of movement.

\section{Subjects}

The Logsdon approach has been used as the basis for the elementary program in a school district in a medium-sized midwestern city. Two expert physical education teachers agreed to allow the investigator to observe their classes taught with the Logsdon approach. Both teachers had been instrumental in developing the district curriculum based on the Logsdon approach and reported that they followed it fairly closely. Each teacher had completed her master's degree with one of the developers of the Logsdon approach. Both had been selected by the district to be involved in the curriculum-writing process and later to lead in- 
service workshops for their colleagues. In addition, both had received distinguished teaching awards from the district. Susan Dillon, the physical education teacher at Meadow Run Primary School, was 43 years of age and had 20 years of teaching experience. Jean Harlan, the physical educator at Foxcroft Elementary, was 38 and had been teaching for 16 years (all names are pseudonyms).

Eight classes of elementary students $(N$ $=153$ ) composed the sample for the study. Classes were selected to represent a typical morning in the school day. Four consecutive physical education classes at Meadow Run School-one kindergarten, one first, and two second grades-were observed; at Foxcroft the four classes observed included one third, one fifth, and two fourth grades. Kindergarten through third-grade students had physical education for 30 minutes twice each week. Fourth- and fifth-grade students participated for 45 minutes on a similar meeting schedule. Schools were racially and culturally diverse under a voluntary paired-school integration plan. Minority students represented $33 \%$ of the enrollment. Twenty-one percent of the students were African-American, $8 \%$ were Asian, $2 \%$ were Hispanic, and $2 \%$ represented other minorities.

\section{Data Collection}

I collected data using observation and interview methods. Four classes in each of the two programs were observed one morning each week over a 6 -month period. Supplementary visits to the morning classes were made at 1-month intervals for an additional 3-month period. Field notes were recorded with an emphasis on teacher and student verbalizations and behaviors. Following the observation period, formal interviews were conducted with teachers. Written documents in the form of the district curriculum, school policy statements, and teacher-designed lesson plans were examined.
In naturalistic research, the investigator's participation can range from total involvement to having no interactions with subjects (Patton, 1980). In this research, I interacted with teachers during noninstructional times. I collected observational data, documenting classroom events while I sat passively at the side of the gymnasium. Field notes were recorded on a small lap computer and then transferred to a microcomputer for analysis. The data files were similar to an ethnographer's field note journal in that they consisted of a description of events and behaviors from a nonparticipant perspective. A second, handwritten journal that included my interpretive comments was also updated daily.

Both informal and formal interviews were used in this study. Informal interviews were part of the daily interactions with teachers. Prior to class, I asked teachers to describe their plans for the lesson and expectations for student learning. Following the class I asked them to evaluate their teaching and their students' progress. I always attempted to remain neutral to both positive and negative comments. These records became part of a third journal (separate from the field note and interpretative journals) in which I recorded the participants' perspectives.

The second type of interview incorporated a 40-minute formal, open-ended format (Spradley, 1979). I interviewed teachers at the conclusion of the 6-month observation period. The interview began with general demographic questions followed by nine standard questions that focused on three themes: $(a)$ the teacher's use of the Logsdon curriculum, $(b)$ the importance of thinking skills within a curriculum that emphasized movement, and $(c)$ the rationale for a teacher's emphasis on particular components of content and for the selection of teaching strategies. The interviews were audiotaped and transcribed for analysis.

\section{Data Analysis}

Observational and interview data were analyzed using the procedures of constant 
comparison (Glaser \& Strauss, 1967) and typological analysis (Goetz \& LeCompte, 1984). Constant comparison is an inductive process that occurs in approximately four phases: (a) comparing incidents and generating categories, $(b)$ integrating categories, (c) delimiting the theory, and $(d)$ writing the theory. In this study, I analyzed the field note and interview data to identify common elements or examples related to thinking skills. Every example that might be construed as contributing to cognitive development was included in the initial scanning phase. Similar examples were then grouped into categories and rescanned in an integrative process to detect common properties. Glaser and Strauss $(1967$, p. 36) defined properties as "concepts indicated by the data" (and not the data themselves). Properties may vary in conceptual abstraction. They are derived from a comparison of similarities and differences within data categories. Examples that did not readily fall into categories were held separately for later analysis. In the third phase, I compared properties across categories to test for the integrity of category membership, thus delimiting the emerging theory. The "writing of the theory" in this study consisted of a presentation of hypotheses or empirical generalizations to address each of the three research questions (Chilcott, 1987). I then used typological analysis to compare the emerging categories with definitions presented in the thinking skills literature. It is important to emphasize that the categories and properties emerged from the data prior to my perusal of the literature and were not revised or modified to fit accepted terminology.

\section{Reliability and Validity}

Threats to reliability and validity of the naturalistic study were addressed systematically (Howe \& Eisenhart, 1990; LeCompte \& Goetz, 1982). External reliability was enhanced by recognizing and focusing on three potential problems: researcher status position, informant choices, and analytic constructs and premises analysis (Goetz \& LeCompte, 1984). Delineation of the researcher status position should include a description of the investigator's affiliations and potential biases. I am a physical educator who has taught in elementary schools. However, because of my association with the university and my strict adherence to the nonparticipatory role, I should be considered an outsider whose role was limited in scope. I am interested professionally in promoting quality physical education and believe that cognition should be emphasized with motor and affective goals. My experience with the Logsdon approach has been limited to studying curriculum questions regarding the model (Ennis, 1990; Ennis, Mueller, \& Hooper, 1990).

Informants were selected because of their expertise in elementary physical education using the Logsdon curriculum. The principal informants were the elementary teachers who had both been trained in the Logsdon approach. A key factor in the external reliability of naturalistic research is the clear delineation of constructs and premises. The ability to locate the presence of constructs documented in this study in other research is dependent on precise and accurate description. In this article operational definitions that remained constant throughout the study, such as basic thinking skills, were described in the introductory section; the cognitive-content relationships examined in the field study will be defined and developed within the remainder of the article.

Problems of internal reliability in naturalistic research focus on the question, To what extent do multiple observers agree? (LeCompte, \& Goetz, 1982). This is especially critical if several research sites are being examined. In this study, access to the school was limited to a single investigator in order to minimize disruption to the classroom and to preserve the natural environment. Four strategies were used to address the threats to the internal reliability of the study. These were the use of low-inference 
descriptors, participant researchers (the two teachers), peer examination, and mechanical recording devices (LeCompte \& Goetz, 1982).

Low-inference descriptors consisted of concrete and precise explanations from observations and direct quotations from interviews. Descriptors were used to provide reviewers, judges, and other researchers with the means to evaluate the conclusions (Goetz \& LeCompte, 1984). Standardized observation and interview protocols were used to increase the consistency of the data. Participant researchers assisted by examining the data and interpretations.

In addition, a colleague experienced in naturalistic research agreed to review all files, journals, and interview transcripts. The reviewer's primary role was to question the interpretations based on the data and offer counterexamples as alternative explanations for occurrences. The fact that the reviewer had never observed the classes nor met the teachers served as a control on my potential biases. The reviewer objectively analyzed the data to determine the extent to which the categories and properties were consistent. The clarity of the narrative and the use of low-inference descriptors facilitated the review. Rigorous examinations of the descriptions, interpretations, and conclusions were used to locate discrepancies and facilitate the search for grounded theory.

The use of mechanical recording devices such as lap computers and tape recorders increased the accuracy of the observation and interview data. I typed data into the lap computer while observing students and teachers. During the interviews, I used a tape recorder to record all information. This permitted me to focus on responses and to structure follow-up questions.

Internal validity was strengthened by the extended period that I spent as an observer in the schools. This permitted continual data collection and comparison of constructs (Goetz \& LeCompte, 1984). Specific interview questions were developed from a direct and thorough knowledge of the interviewer's teaching environment. Changes that occurred in the environment during the observation were monitored and compared with baseline observations recorded prior to the change.

Threats to internal validity of the study were met through triangulation procedures within each school. The research design called for the reporting of critical events from my perspective and that of the teacher. I compared field notes, interview results, and interpretations to identify both positive and negative instances that either supported or refuted theoretical constructs.

Triangulation procedures were also used to address the threats to the external validity of the research. The study of two schools provided the opportunity to examine the phenomena in two locations. Findings from two sites studied concurrently supported the reliability of observations and enhanced the cross-site validity of the findings (Campbell, 1979). The sites were selectively sampled from the 27 elementary schools in the district to reflect cultural diversity within the student population. Results presented in this article are limited to those constructs and behaviors that were documented independently at both sites.

\section{Results and Discussion}

In this study, physical educators using the Logsdon curriculum structured the environment to emphasize several characteristics of basic thinking skills. They employed teaching strategies that emphasized both inductive and deductive methods. Properties of thinking skills identified in these physical education programs were consistent with characteristics of discrete thinking skills documented in the literature.

\section{Thinking Skills}

Analysis of the data from two programs indicated that teachers encouraged cognitive involvement of their students with the movement content. Teachers verbally encouraged students to focus their attention 
on movement skills and structured the physical education classroom to elicit thinking behaviors.

Both teachers emphasized metacognition by assisting students to manage and adjust their work. Properties of the data to support the hypothesis are reported in the right column of Appendix A. Managing involved (a) directing students' attention to the movement pattern, $(b)$ encouraging students to identify errors, and $(c)$ integrating the movement within a larger sequence. An example of managing occurred as students incorporated different locomotor patterns into repeatable sequences. In Susan Dillon's class, kindergarten students selected locomotor patterns, such as a jump, hop, and leap, to combine into movement sequences. Students were asked to perform the pattern and identify errors based on a criterion for a good performance (i.e., jump-landing on two feet; hop-take off and land on the same foot; and leap-take off on one foot and land on the other). Students then combined the patterns into a sequence and performed the sequence correctly three times.

Four properties of the adjusting category were observed in these physical education programs. Both teachers emphasized adjusting by assisting students to $(a)$ focus their attention on thinking about movement, $(b)$ explore characteristics of movement, and (c) draw conclusions regarding the effectiveness of the movement or strategy in given situations. Adjusting usually occurred over several class periods. I discuss examples of each of these properties as focusing attention, exploring movement characteristics, and drawing conclusions.

Focusing attention usually involved three components. First, teachers reminded students that physical education was an educational class, not recess. Second, students were frequently reminded to "think" or to "use their minds" to understand and solve movement problems. Third, students were encouraged to understand movements better by observing, feeling, and listening. Emphasis on the visual, auditory, and kinesthetic aspects of moving was critical in enabling students to gather information they would need later. For example, Jean Harlan encouraged third graders to concentrate on the strategies required to be good "interceptors" of objects in game situations:

Jean Harlan: You are beginning to think, and your body is beginning to warm up. Throwers, pass the ball to other throwers. If you are not a thrower, your job is to try to catch or intercept the ball ... . sTop! Now, who can tell me some strategies for being a good interceptor?

Harold: Stand behind the catchers and jump in front of them.

Susan: You can jump in front of them at the last second and catch the ball.

Robert: You can follow the throwers around so you can intercept their passes.

Jean Harlan: That is called player-to-player defense. You recognize certain kinds of throws and can intercept the ball because you know what is going to happen. Now let's try our game again and use these strategies to be good interceptors.

The interview with the teacher at the conclusion of the study confirmed the importance of directing students' attention to the academic components of movement education: "I consider physical education to be an academic subject. Students should learn to think about and analyze movement patterns. I have very specific objectives each day that I expect my students to learn and remember. I begin to create this atmosphere when I get them as kindergartners. We have fun, but we come to work and learn. Students who transfer in from other school districts must adjust to the fact that we don't spend all of our time playing games."

The property of "exploring movement characteristics" (in the adjusting category) received the strongest support in the observational data. Examples from field notes were classified as comparing/contrasting, categorizing, analyzing, and recognizing re- 
lationships. Students explored movement patterns through a variety of teacher-structured activities. First-grade students in $\mathrm{Su}$ san Dillon's class, for example, spent several class periods categorizing locomotor patterns involving flight. Flight occurred when a student's feet or body completely left the ground. Locomotor patterns (on the feet) in this category include jumps, hops, leaps, and skips. First graders compared takeoff and landing patterns for each movement. Working with the teacher, they analyzed classmates' patterns, named each pattern, and provided a rationale for categorization. Movements involving flight were later combined with other locomotor patterns to make repeatable sequences.

Students' ability to draw conclusions, the third property of the adjusting category, was observed primarily through motor performance, not through verbalization as in other subjects. Drawing conclusions required students to compare their performances with a stated criterion or standard. Susan structured the difficulty of tasks to reflect the range of abilities of students in a particular class. At times, she spent as much as one-quarter of the class period explaining the criteria and encouraging student demonstrations of both good performances and those that required "additional practice." Kindergarten, first-, and second-grade students were invited to select tasks that were compatible with their ability. In order to do this, they were first asked to perform a skill, such as vaulting over a bench. If they completed the vault without permitting their feet or legs to touch the bench (criterion for good performance), they could move to the next most difficult level. As she moved around the gymnasium, Susan emphasized three properties that were essential when drawing conclusions: she $(a)$ reminded students of the criterion, $(b)$ asked them to think about their performance, and (c) encouraged them to decide whether they should move to an "easier or more difficult place to work." It was doubtful whether these young students were really involved in the complex operations of problem solving or decision making. However, it was clear to me that they were carefully considering the alternatives and monitoring and regulating their performance based on the stated criterion.

The cognitive focus evident in these classes was similar to the concept of metacognition. Flavell (1976, p. 276) defined metacognition as the learner's personal knowledge concerning his or her "own cognitive processes or products." Presseisen (1985) has elaborated this definition to include the use of monitoring and regulating to compare performance with stated objectives. Characteristics of metacognition are summarized in the left column of Appendix A. According to Presseisen, monitoring includes keeping one's place in the sequence, detecting and correcting errors, and pacing one's work. Regulating emphasizes skills that focus attention on the required topic, relate the known to the unknown, and test the correctness of the strategy. These skills have typically been associated with the teacher's role rather than that of the student. When responsibility for monitoring and regulating performance is transferred to the student, the teacher's role becomes one of facilitation. According to Costa (1984), this ability to monitor and regulate one's own performance is a key attribute of formal thinking or cognitive process skills.

Sternberg (1983) confirmed that metacognitive skills improve when students develop their own strategies and practice them while performing interesting and relevant tasks. Student-generated thinking in response to the demands of a task or task criteria appears to be beneficial. Susan Dillon and Jean Harlan encouraged students to monitor and regulate their own performances. The thinking skills were useful in making decisions regarding sequencing and self-evaluation based on the content of the Logsdon curriculum. In Appendix A data categories have been juxtaposed with Presseisen's (1985) categories of monitoring and regulating. Similarities are evident between 
the categories of managing and monitoring, and adjusting and regulating.

\section{Strategies for Teaching Thinking Skills}

Although these physical education teachers used a variety of methods to encourage thinking, such as questioning and multiple-ability tasks, analysis of the data indicated that many of the strategies could be grouped within comprehensive categories of deductive and inductive teaching methods.

Teaching methods that involved deductive strategies typically included an explicit statement of skill components in the initial introduction. Conversely, inductive strategies allowed students to articulate for themselves the key attributes of the skill. The deductive strategy was exemplified previously in Susan Dillon's use of specific criteria in the vaulting task. Students were asked to use the criteria to evaluate the quality of their performance and make adjustments. In this instance, Susan $(a)$ introduced the vaulting skill and $(b)$ explained the steps and components. Then she asked her students to $(c)$ demonstrate the skill, $(d)$ practice it, $(e)$ compare their performance with the criteria, and $(f)$ decide on the height of the next vault. A summary of these properties is presented in the right column of Appendix B.

I observed inductive strategies frequently in these physical education classes taught with the Logsdon curriculum. Teachers typically structured the learning situation so that students were required to identify key elements necessary for successful performance and then to incorporate them in their own performance. Teachers assisted students to $(a)$ focus on other students' examples of good performance, $(b)$ analyze additional criteria, and $(c)$ incorporate criteria in the next performance.

Jean Harlan used an inductive strategy to introduce the concept of dodging in her fourth-grade class. Students were asked to determine which techniques or strategies were most effective in moving around other people or objects. Within a confined space, students moved slowly at first and then more rapidly without touching anyone. As the speed requirements increased, students immediately began changing directions more quickly and shifting their weight in anticipation of the next direction change. In this instance the unique characteristics of the task elicited the correct response. However, when students were asked initially to describe how they were avoiding others, most responded, "You just go around them."

Jean then asked students to think more about their movement patterns and to identify a strategy they used to avoid others. The second time the activity was stopped, students responded with a more varied and sophisticated analysis of the movement patterns employed. For example, one fourth grader demonstrated how he tucked his shoulder as he changed direction. A second student noted that your "feet needed to be apart and your weight back if you are going to stop (before changing direction)." Jean continued to increase the difficulty of the dodging activity by adding equipment and additional tasks to perform while dodging (i.e., tossing and catching a ball). In this example, students experimented with the skill before the teacher formally introduced it. As the teacher and students discussed events that were occurring, the components of the dodging skill gradually emerged. Once students stated a strategy explicitly, the teacher then reminded them to incorporate it during subsequent attempts.

The thinking skills elicited through deductive strategies encouraged and influenced the extent to which metacognition occurred. Placing students in interesting situations with problems that they were eager to solve appeared to facilitate both the use of thinking skills and the students' ability to perform the movement task. During the final interview, Susan Dillon articulated her rationale for the inclusion of thinking skills: "Highly skilled athletes are good thinkers. They understand what they must 
do to be successful and have developed the movement skills to allow their body to follow their brain's commands. I feel my students learn movement skills faster when they are analyzing and thinking about the movement. Teaching students to think about movement is just a natural part of my class."

According to Beyer (1985), the deliberate use of inductive and deductive strategies can contribute to the development of thinking skills in social studies and other subjects. Beyer described deductive and inductive teaching as an interactive process between teachers and students that can occur in a systematic series of steps. The steps Beyer outlined were similar to the properties that emerged from data collected in this study (see App. B).

There were a few differences in the descriptions of deductive teaching styles between Beyer's categories and the field notes based on my observations. A comparison of properties of inductive strategies, however, revealed additional techniques that these teachers used to guide students' learning. For example, Beyer suggested that teachers should first introduce the skill, encourage student experimentation, and invite students to think reflectively about how they were performing. Susan and Jean appeared to refine this process by structuring the task so that students' attention was directed toward key elements necessary for correct performance. Moreover, teachers assisted students to improve their performance by analyzing the performances of others and isolating critical components.

\section{Classification of Thinking Skills}

In this study the data were collected and analyzed prior to the identification of theory. The specific literature related to metacognition and inductive/deductive methods helped me to make sense of the extensive field notes. However, it was of limited use when classifying data properties within the larger body of thinking skills literature. Within that literature, some schol- ars limited the categorization of cognitive skills to critical thinking skills in which identification of central issues, recognition of assumptions, and evaluation of evidence play a primary role (e.g., Ennis, 1962). Creative thinking skills such as fluency, flexibility, originality, and elaboration (Torrance, 1980) were also cited as additional components of the thinking process.

The thinking skills documented in the two elementary physical education programs reported here did not possess the sophistication needed for complex reasoning and critical thinking required by Ennis (1962). Although this orientation may be possible in secondary and postsecondary physical education, it is unlikely to occur in elementary physical education classes. Likewise, although it is possible to generate creative thinking skills as part of physical education (Brockmeyer, 1987), creative thinking was not a stated objective of the programs examined.

An analysis of the data from this study suggested that skills documented were quite basic and did not include the complex operations defined in critical thinking. However, the observed skills important in the development of thinking might well be described as readiness skills for more complex operations. Several schema related to teaching of thinking readiness or preparation for thinking appeared to hold promise for classification of thinking skills observed in these programs. Feuerstein's (1980) Instrumental Enrichment Cognitive Functions Taxonomy was consistent with the categories generated in the constant comparison analysis. Savell, Twohig, and Rachford (1986) conducted an extensive review of the research on "Feuerstein Instrumental Enrichment." Costa (1985) simplified Feuerstein's categories to facilitate use by teachers in the classroom. This modification was selected because it was most compatible with the teaching-learning environment.

The Costa (1985) modification presents a hierarchy of thinking skills in four levels. Level 1 consists of discrete thinking skills 
including input of data, elaboration of data, and products of elaborations. Level 2 identifies five thinking strategies or operations: problem solving, critical thinking, decision making, strategic reasoning, and logic. Level 3 is composed of creative thinking skills that include the generation of unique products and innovative solutions to problems. Level 4, the cognitive spirit, emphasizes the importance of the impetus and commitment to think. This level includes the qualities of open-mindedness, honesty, searching for alternatives, acceptance of ambiguity, and insistence on precision.

When the data from this study were reanalyzed using this classification system, the categories and properties identified were most consistent with level 1 , discrete thinking skills. A comparison of level 1 of the modified taxonomy and the properties generated in this research is presented in Appendix C. Costa's level 1 categories appear to be most consistent with the adjusting category generated from the data. The level 1 subcategory entitled "Input of Data" closely paralleled the attention-focusing property discussed earlier. The input category included gathering data through the senses (listening, smelling, tasting, and feeling) and being alert to problems, discrepancies, and dilemmas (Costa, 1985). In the study reported here, both teachers assisted students to focus on the importance of thinking while moving and receiving information visually, auditorially, and kinesthetically.

The property "exploring movement characteristics" identified within the adjusting category closely paralleled the "elaborating" subcategory in Costa's taxonomy. Elaborating included comparing/ contrasting, analyzing/synthesizing, classifying/categorizing, inducing/deducing, and perceiving relationships (e.g., temporal, spatial, and seriational). I identified numerous examples of comparing/contrasting, analyzing, and categorizing. The importance of relationships was included as a category of the curriculum approach (Laban,
1971; Logsdon et al., 1984), and many instances of spatial, temporal, and sequential relationships were documented. However, the inducing/deducing category was attributed more to teaching strategies than to student-initiated use of thinking skills.

The "output" subcategory in level 1 was most difficult to support with field notes and interview data. This category, composed of skills such as inferring, hypothesizing, predicting, concluding, and evaluating, was not represented as broadly as the input and elaboration subcategories. I could not document inferring and hypothesizing through any direct examples. Predicting may have occurred as students monitored their abilities and selected the next level at which they should be successful. However, it is more likely that these decisions should be classified as monitoring or evaluating because students often moved on to the next task after they had met the criteria, without making an effort to predict success at the next level. By providing experiences that assist students to infer, hypothesize, and predict, these physical education teachers could offer students additional opportunities to use discrete thinking skills.

Presseisen (1985) suggested that skills associated with levels 2 and 3 of the modified taxonomy are more appropriate for middle and secondary students. She argued that elementary schools should focus on discrete level 1 thinking skills, just as the teachers in these physical education programs were doing. Although it may be argued that Susan and Jean were structuring situations in which students practiced the level 2 strategies of problem solving and decision making, the field notes and interviews did not provide evidence that the teachers taught or intended to teach these processes to students (Presseisen, 1985).

\section{Implications for Elementary Physical Education}

As the integrated approach to teaching discrete thinking skills continues to receive attention at the elementary level, the contri- 
bution of the nonacademic subjects in meeting these goals should not be ignored. Although there is much evidence supporting the contribution of physical education to the physiological, psychological, and sociological development of the elementaryage child (e.g., Albinson \& Andrews, 1973; Vogel, 1986), the cognitive development of students has previously been left to more academic subjects. The theoretical curriculum structure of the Logsdon approach coupled with the use of inductive and deductive strategies is effective in the presentation of discrete thinking skills in physical education. In this study, expert teachers were observed and interviewed with a focus on thinking skills. The emphasis on the teaching of discrete thinking skills was already part of their teaching repertoire. In-service programs would be appropriate to assist these teachers to provide additional experiences that encourage thinking during the "output" portion of the task or lesson and to articulate the components of problem solving and decision making.
Discrete skills that encourage students to perceive, elaborate, and communicate information for thinking can be included in elementary physical education. Limited school budgets and time restraints require that every subject contribute to the total education of each child. Physical education at the elementary level should nurture the cognitive development of students as well as contribute to the development of positive values, fitness, and motor goals. The use of theoretically structured curriculum approaches with appropriate inductive and deductive teaching methodologies can increase the cognitive involvement of students in physical education. The introduction, support, and maintenance of discrete thinking skills are realistic goals for elementary physical education. Curriculum coordinators, principals, and classroom teachers should support the efforts of physical educators to incorporate these skills into physical education.

\section{Appendix A}

\section{Comparison of Metacognitive Characteristics with Properties of the Data}

\section{Characteristics of Metacognition (from Presseisen, 1985, p. 46)}

Monitoring:

1. Keep place in the sequence

2. Detect and correct errors

3. Pace work

\section{Regulating:}

1. Focus attention on required topic

2. Relate known to the unknown

3. Test the correctness of the strategy

\section{Categories and Properties}

Generated from the Data

Managing:

1. Focus on movement pattern

2. Identify errors

3. Integrate movement with a larger sequence

Adjusting:

1. Focus attention on thinking about movement

2. Explore movement characteristics

3 . Draw conclusions regarding the effectiveness of the movement or strategy in a given situation 


\section{Appendix B}

\section{Comparison of Inductive and Deductive Teaching Methods with Properties of the Data}

Characteristics of Deductive and Inductive Teaching Methods (from

Beyer, 1985, pp. 298-300)

Deduction

Teacher:

1. Introduced the skill

2. Explained components, procedures, and rules of the skill

3. Demonstrated skill

Student:

4. Applied the skill following the rules

5. Reflected about the thinking process as skill was executed

6. Made decision regarding next performance

Induction

1. Teacher introduced the skill

2. Students experimented with skill

3. Students reflected on thinking process as skill was executed

4. Applied this new knowledge as skill was performed

5. Reflected on thinking process as skill was executed
Categories and Properties Generated from the Data

Deduction

Teacher:

1. Introduced the skill

2. Explained the steps or components (criteria)

Student:

3. Demonstrated skill

4. Practiced skill

5. Compared performance to criteria

6. Selected the next task

Induction

1. Teacher structured situation that required:

a. identification of key elements prior to successful performance

b. incorporation of new knowledge in next performance

2. Teacher assisted students to:

a. focus attention on other students' examples of successful performance

b. analyze skill and isolate critical components

c. incorporate new knowledge in next performance.

\section{Appendix C}

\section{Comparisons of Thinking Skill Characteristics with Properties of the Data}

Costa's Modification of Feuerstein's

Taxonomy (from Costa, 1985, pp. 67-

68)

Level 1: Discrete thinking skills

1. Input of data

a. Gathering data through the senses

b. Being alert to problems, discrepancies

c. Being fascinated by the environment

2. Elaborating (processing the data)
a. Comparing/contrasting
b. Analyzing/synthesizing
c. Classifying/categorizing
d. Inducing/deducing
e. Perceiving relationships

3. Output of the products of elaboration
a. Inferring

Categories and Properties Generated from the Data

Adjusting:

1. Attention focusing

a. Focus on thinking while moving

b. Attending to sensory information (visual, auditory, kinesthetic)

2. Exploring movement characteristics
a. Comparing/contrasting
b. Analyzing
c. Categorizing
d. Teaching strategies
e. Recognizing relationships

3. Concluding a. Monitoring/evaluating effectiveness of
performance 

b. Hypothesizing
c. Predicting/forecasting/extrapolating
d. Concluding/generalizing/summariz- ing
e. Evaluating

b. Regulating performance based on criteria
Notes

This research was funded by a grant from the Wisconsin Alumni Research Foundation. Special thanks are extended to the teachers and students who participated in this study. The author was a faculty member at the University of Wisconsin-Madison at the time this research was conducted.

\section{References}

Albinson, J. G., \& Andrews, G. M. (Eds.). (1973). The national conference on the child in sport and physical activity. Toronto: Canadian Council on Children and Youth.

Beyer, B. K. (1987). Teaching critical thinking: A direct approach. Social Education, 49, 297303.

Brockmeyer, G. (1987). Creativity in movement. Journal of Teaching in Physical Education, 6, 310-319.

Campbell, D. T. (1979). "Degrees of freedom" and the case study. In. T. D. Cook \& C. S. Reichardt (Eds.), Qualitative and quantitative methods in evaluation research (pp. 49-67). Beverly Hills, CA: Sage.

Chilcott, J. H. (1987). Where are you coming from and where are you going? The reporting of ethnographic research. American Educational Research Journal, 24, 199-218.

Costa, A. L. (1984). Mediating the metacognitive. Educational Leadership, 42(3), 57-62.

Costa, A. L. (1985). The behaviors of intelligence. In A. L. Costa (Ed.), Developing minds (pp. 66-68). Alexandria, VA: Association for Supervision and Curriculum Development.

Ennis, C. D. (1990). Analyzing curriculum as participant perspectives. Journal of Teaching in Physical Education, 9, 79-94.

Ennis, C. D., Mueller L. K., \& Hooper, L. (1990). The influence of teacher value orientation on curriculum planning within the parameters of a theoretical framework. Research Quarterly for Exercise and Sport, 62, 170-187.
Ennis, R. H. (1962). A concept of critical thinking. Harvard Educational Review, 32(1), 81111.

Ennis, R. H. (1985). Goals for a critical thinking curriculum. In A. L. Costa (Ed.), Developing minds (pp. 54-57). Alexandria, VA: Association for Supervision and Curriculum Development.

Feuerstein, R. (1980). Instrumental enrichment: An intervention program for cognition modifiability. Baltimore: University Park Press.

Flavell, J. H. (1976). Metacognitive aspects of problem solving. In. L. B. Resnick (Ed.), The nature of intelligence (pp. 231-236). Hillsdale, NJ: Erlbaum.

Glaser, B. G., \& Strauss, A. L. (1967). The discovery of grounded theory: Strategies for qualitative research. New York: Aldine.

Glatthorn, A. A. (1985). Thinking and writing: The elusive but important connection. In F. R. Link (Ed.), Essays on the intellect (pp. 67-88). Alexandria, VA: Association for Supervision and Curriculum Development.

Goetz, J. P., \& LeCompte, M. D. (1984). Ethnography and qualitative design in educational research. Orlando, FL: Academic Press.

Howe, K., \& Eisenhart, M. (1990). Standards for qualitative (and quantitative) research: A prolegomenon. Educational Researcher, 19(4), 2-9.

Jacob, E. (1987). Qualitative research traditions: A review. Review of Educational Research, 57, $1-50$.

Jones, B. F. (1985). Reading and thinking. In A. L. Costa (Ed.), Developing minds (pp. 108113). Alexandria, VA: Association for Supervision and Curriculum Development.

Laban, R. (1971). Mastery of movement (3d ed.). Revised by L. Ullman. London: Unwin Brothers.

LeCompte, M. D., \& Goetz, J. P. (1982). Problems of reliability and validity in ethnographic research. Review of Educational Research, 52, 31-60.

Logsdon, B. K., Barrett, K., Ammons, M., Broer, M. R., Halverson, L. E., McGee, R., \& Roberton, M. A. (1984). Physical education for children. Philadelphia: Lea \& Febiger.

Marzano, R. J., Brandt, R. S., Hughes, C. S., Jones, B. F., Presseisen, B. Z., Rankin S. C., 
\& Suhor, C. (1988). Dimensions of thinking: A framework for curriculum and instruction. Alexandria, VA: Association for Supervision and Curriculum Development.

Patton, M. Q. (1980). Qualitative evaluation methods. Beverly Hills, CA: Sage.

Perkins, D. N., \& Salomon, G. (1989). Are cognitive skills context-bound? Educational Researcher, 18(1), 16-25.

Pitt, R. B. (1983). Development of general problem-solving schema in adolescence and early adulthood. Journal of Experimental Psychology, 112, 547-584.

Polya, G. (1957). How to solve it: A new aspect of mathematical method. Garden City, NY: Doubleday.

Presseisen, B. Z. (1985). Thinking skills: Meanings, models, materials. In A. L. Costa (Ed.), Developing minds (pp. 43-48). Alexandria, VA: Association for Supervision and Curriculum Development.

Safrit, M. J., Ennis, C. D., \& Nagle, F. (1988). The use of problem solving skills in computeraided instruction: An evaluation. Journal of Computer Assisted Learning, 4, 227-243.

Savell, J. M., Twohig, P. T., \& Rachford, D. L. (1986). Empirical status of Feuerstein's "instrumental enrichment" (FIE) technique as a method of teaching thinking skills. Review of Educational Research, 56, 381-409.

Schoenfeld, A. H., \& Herrmann, D. J. (1982). Problem perceptions in knowledge structure in expert and novice mathematical problem solvers. Journal of Experimental Psychology: Learning, Memory and Cognition, 8, 484-494.

Solomon, W. (1987). Improving students' thinking skills through elementary social studies instruction. Elementary School Journal, 87, 557-569.

Spradley, J. (1979). The ethnographic interview. New York: Holt, Rinehart \& Winston.

Sternberg, R. J. (1983). How can we teach intelligence? Philadelphia: Research for Better Schools.

Sternberg, R. J. (1985). Critical thinking: Its nature, measurement and improvement. In F. R. Link (Ed.), Essays on the intellect (pp. 45-65). Alexandria, VA: Association for Supervision and Curriculum Development.

Torrance, E. P. (1980). The search for satori and creativity. Buffalo, NY: Creative Educational Foundation.

Vogel, P. G. (1986). Effects of physical education programs on children. In V. Seefeldt (Ed.), Physical activity and well being. Reston, VA: American Alliance for Health, Physical Education, Recreation and Dance.

Wirtz, R. (1985). Some thoughts about mathematics and problem solving. In A. L. Costa (Ed.), Developing minds (pp. 97-101). Alexandria, VA: Association for Supervision and Curriculum Development. 